\title{
An Experimental and Theoretical Investigation of the Skeletal Frequencies of the Paraffin Hydrocarbons and the Far Infra-Red Spectrum of Carbon Tetrachloride
}

\author{
David M. Gates \\ Department of Physics, University of Michigan, Ann Arbor, Michigan*
}

(Received September 9, 1948)

\begin{abstract}
The far infra-red spectra of the paraffin hydrocarbons and of carbon tetrachloride have been investigated. The following bands were located: propane at $370.6 \mathrm{~cm}^{-1}, n$-butane at $215 \mathrm{~cm}^{-1}$, and carbon tetrachloride at $315 \mathrm{~cm}^{-1}$, the latter showing isotope structure. The contours of the following near infra-red bands for $n$-butane were surveyed, and some fine structure was revealed: $1342.9 \mathrm{~cm}^{-1}$, $1295.6 \mathrm{~cm}^{-1}, 1135.6 \mathrm{~cm}^{-1}, 956.5 \mathrm{~cm}^{-1}$, and $740.0 \mathrm{~cm}^{-1}$. The assignment of the skeletal frequencies of vibration is made, and a theoretical analysis of the skeletal normal frequencies, assuming a valence potential for the molecules propane through pentane, is given.
\end{abstract}

\section{INTRODUCTION}

$\mathbf{N}$ UMEROUS investigations of the infra-red and Raman spectra of the normal paraffin hydrocarbons have been reported. ${ }^{1}$ The complete assignment of the normal frequencies for ethane and propane have been made (references to these are given later), although the exact symmetry configuration of ethane is still in doubt. Eliashevich and Stepanov ${ }^{2}$ have given the analysis of all the normal frequencies of $n$-butane. Two main difficulties plagued previous investigators-the absence of the low frequency infra-red data and the lack of knowledge concerning the structure of the infra-red bands, as well as the depolarization factors for the Raman bands. Kirkwood, ${ }^{3}$ Whitcomb, Nielsen, and Thomas, ${ }^{4}$ Pitzer, ${ }^{5}$ Barriol, ${ }^{6}$ and Kellner ${ }^{7}$ have made use of the periodicity present in these molecules to treat them as finite segments of an infinite chain after the method of Born and Karman. This method could not convincingly identify the fundamental frequencies of the model with the observed bands, but may result in considerable usefulness after the shorter members of the series have been accurately analyzed. Recently Rasmussen, ${ }^{8}$ Sheppard, ${ }^{9}$ and Szasz, Sheppard, and $\operatorname{Rank}^{10}$ have given analyses of the butanes and pentanes. Ahonen ${ }^{11}$ gave a theoretical evaluation of the isomeric octanes. Kohlrausch and $\mathrm{Köppl}^{12}$ gave

* Now at the Department of Physics, University of Denver, Colorado.

1 George Herzberg, Infrared and Raman Spectra of Polyatomic Molecules (D. Van Nostrand Company, Inc., New York, 1945).

${ }^{2}$ M. Eliashevich and B. Stepanov, Comptes Rendus U.R.S.S. 32, 481 (1941).

3 J. G. Kirkwood, J. Chem. Phys. 7, 506 (1939).

${ }_{4} \mathrm{~S}$. E. Whitcomb, H. H. Nielsen, and L. H. Thomas,

J. Chem. Phys. 8, 143 (1940).

${ }^{5}$ K. S. Pitzer, J. Chem. Phys. 8, 711 (1940).

${ }^{6} \mathrm{~J}$. Barriol, J. de phys, et rad. 10, 215 (1939).

7 L. Kellner, Trans. Faraday Soc. 41, 217 (1945).

8 R. S. Rasmussen, J. Chem. Phys. 16, 712 (1948).

${ }^{9}$ N. Sheppard, J. Chem. Phys. 16, 690 (1948).

${ }^{10}$ G. J. Szasz, N. Sheppard, and D. H. Rank, J. Chem. Phys. 16, 704 (1948).

11 C. O. Ahonen, J. Chem. Phys. 14, 625 (1946).

${ }^{12} \mathrm{~K}$. W. F. Kohlrausch and F. Köppl, Zeits. f. physik. Chemie B26, 209 (1934). a theoretical analysis of the hydrocarbons propane through heptane with experimental data listed through dodecane. The near infra-red prism spectra for the hydrocarbons all may be obtained from the American Petroleum Institute Research Project No. 44 through the National Bureau of Standards.

The purpose of the present investigation was to analyze only the skeletal frequencies of the normal paraffin hydrocarbons. Attention was concentrated on the skeletal motions as a result of the lack of fine structure data concerning the hydrogen bands enabling a classification of them and the complexity of the calculations when these are included. It became immediately clear that before one proceeded with the theoretical analysis of the normal modes of vibration the low frequency bending vibrations in the range $400 \mathrm{~cm}^{-1}$ to $200 \mathrm{~cm}^{-1}$ had to be established and some of the higher frequency skeletal bands further resolved.

\section{EXPERIMENTAL}

The far infra-red region of the spectrum has been studied relatively little and projects many diffculties, the greatest being the lack of transmitting materials for use as windows and prisms. The instrument used for these studies in the far infra-red was the large aperture grating instrument at the University of Michigan, described by Randall and Firestone. ${ }^{13}$ The bending modes of the skeletal vibrations for the normal paraffin hydrocarbons are relatively weak, necessitating a long path length for the radiation through the gas. This was accomplished by filling the entire spectrometer case with the gas, except for the source and focusing mirror, yielding a path length of 460 centimeters. The source box, containing the electrically heated Chromel ribbon strip as a source and a mirror to focus the radiation on the entrance slit, was separated from the spectrometer proper by a thin window. Silver chloride was transparent to about $32 \mu$ and beyond

${ }^{13}$ H. M. Randall and F. A. Firestone, Rev. Sci. Inst. 9, 404 (1938). 


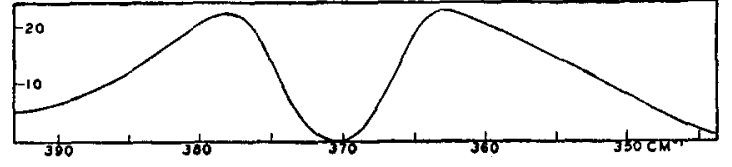

FIG. 1. $n$-Propane gas, $27-\mu$ band.

this wave-length Nylon film 0.2 mil thick was extremely transparent, could withstand a $\frac{1}{3}$-atmosphere pressure differential, simultaneously being heated by the source. This Nylon film was far superior to any other material such as Pliofilm or cellulose nitrate by virtue of its ability to withstand heat. A further difficulty encountered was the dissolving of the stopcock grease sealing the thermopile by the hydrocarbon gases and carbon tetrachloride gas introduced into the spectrometer. The optical path through the spectrometer contained the following elements in this order: an adjustable entrance slit, a push-pull type shutter, a large aperture parabolic collimating mirror 24 inches in diameter and 35 inches in focal length, and a grating of the echelette type with an area of 10 inches by 20 inches ruled on a solder surface. After reflection from this grating, the radiation returned to the large mirror, then was reflected from a restrahlen plate, and focused upon the exit slit. The radiation from the exit slit diverged to an elliptical mirror and was then focused upon the thermopile receivers. The thermopile was of the Pfund type of tin-bismuth and tinantimony coated with Aquadag. The four junctions were connected with the upper pair in series opposition with the lower pair. A single stage Firestone ${ }^{14}$ amplifier with photographic recording was used.

Two methods of calibration of the instrument allowed an accurate measurement of the frequencies: the determination from the grating constant and position and the calibration by the rotation spectrum of water vapor, which has a great many lines throughout this wave-length region. ${ }^{15}$ The water vapor spectrum was associated with each spectrum of the gases investigated, since the complete elimination of water in a gas is practically impossible. Only when the spectrometer was well evacuated and outgassed was the water vapor

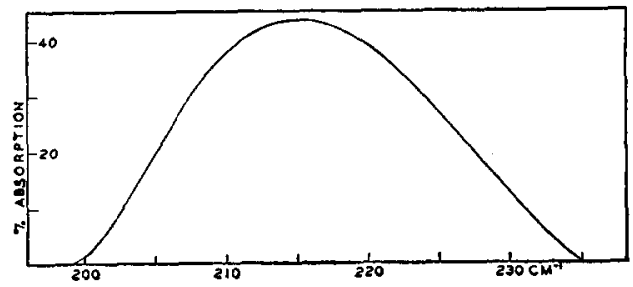

FIG. 2. $n$-Butane gas, $46.5-\mu$ band.

${ }^{14}$ F. A. Firestone, Rev. Sci. Inst. 3, 163 (1932).

${ }_{15}$ Randall, Dennison, Ginsburg, and Weber, Phys. Rev. 52, 160 (1937). spectrum absent. For each of the following molecules studied the entire spectrum from $400 \mathrm{~cm}^{-1}$ to 170 $\mathrm{cm}^{-1}$ was carefully scanned, and only the bands shown here were found.

For propane it is known that a Raman line exists at $373 \mathrm{~cm}^{-1}$. The symmetry type of this molecule allows the infra-red activity of this frequency and the band shown in Fig. 1 with center at $370.6 \mathrm{~cm}^{-1}$ was obtained. The propane was introduced into the spectrometer proper, giving a $460-\mathrm{cm}$ path length at a gas pressure of $39 \mathrm{~cm} \mathrm{Hg}$. A grating with 900 lines per inch was used, $3.0-\mathrm{mm}$ slits, $\mathrm{KCl}$ shutter, $\mathrm{CaF}_{2}$ restrahlen plate, and $\mathrm{AgCl}$ entrance window. Only a single band was found in the region $25 \mu$ to $50 \mu$.

For $n$-butane gas the spectrometer case was filled to a pressure of $46 \mathrm{~cm}$ and the source box with $47 \mathrm{~cm}$ of nitrogen gas. This was necessitated by the use of a Nylon entrance window for the investigation beyond $33 \mu$. A grating with 600 lines per inch was employed, $3.0-\mathrm{mm}$ slits, $\mathrm{KCl}$ shutter, and $\mathrm{CaF}_{2}$ restrahlen plate. For $n$-butane the far infra-red band at $215 \mathrm{~cm}^{-1}$ shown in Fig. 2 was found. Its general contour was that expected for a band with symmetry type $B_{u}$ belonging to an asymmetric top moleculethat is, a hybrid band as a mixture of the usual type $A$ and type $B$ band, although no fine structure was observed. The entire spectrum from $400 \mathrm{~cm}^{-1}$ to 170 $\mathrm{cm}^{-1}$ was carefully scanned and only the single band was found. Normal pentane gas was introduced into the spectrometer at 24.4 centimeters pressure with a path length of 460 centimeters. No bands were found for pentane, probably because they were too weak.

The low frequency fundamental for carbon tetrachloride had been located in the Raman spectrum at $314 \mathrm{~cm}^{-1}$ (see Kohlrausch ${ }^{16}$ ). The present investigation located a band in the infra-red at $315 \mathrm{~cm}^{-1}$ shown in Fig. 3. Barchewitz and Parodi ${ }^{17}$ found this band at $305 \mathrm{~cm}^{-1}$ and other additional bands at 217 $\mathrm{cm}^{-1}, 247 \mathrm{~cm}^{-1}, 370 \mathrm{~cm}^{-1}$, and $529 \mathrm{~cm}^{-1}$. These last few bands were not discovered in the present investigation, nor any evidence that they might be in the spectrum at those positions. The method of obtaining the carbon tetrachloride spectrum of Barchewitz and Parodi allows some suspicion as to

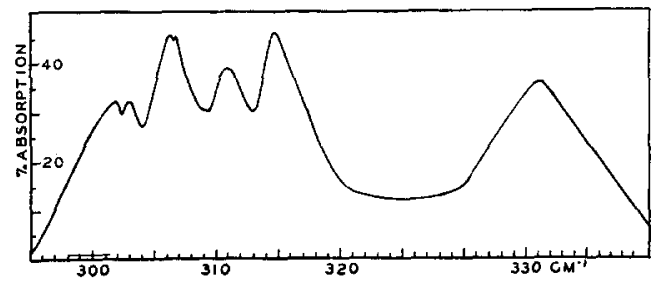

FIG. 3. Carbon tetrachloride gas, $32-\mu$ band.

${ }^{16} \mathrm{~K}$. W. F. Kohlrausch, Der Smekal-Raman-Effect (Verlag. Julius Springer, Berlin, 1931).

${ }_{17}$ P. Barchewitz and M. Parodi, J. de Phys. 10, 143 (1939). 
TABLE I. Interpretation of the infra-red frequencies.

\begin{tabular}{clcc}
\hline \hline $\begin{array}{c}\text { Frequency in } \\
\mathrm{cm}^{-1}\end{array}$ & & $\begin{array}{c}\text { Symmetry } \\
\text { type }\end{array}$ & Figure \\
\hline 1342.9 & $(m) Q$ & $B_{u}$ & 7 \\
1295.6 & $(m) Q$ & $B_{u}$ & 7 \\
1135.6 & $(m)$ & $A_{u}$ & 6 \\
956.5 & $(s) Q$ & $B_{u}$ & 5 \\
740.0 & $(m)$ & $B_{u}$ & 4 \\
215.0 & $(w)$ & $B_{u}$ & 2 \\
\hline
\end{tabular}

the occurrence of these bands. The Raman spectrum gives a band at $314.0 \mathrm{~cm}^{-1}$.

The experimental difficulties encountered with $\mathrm{CCl}_{4}$ were similar to those with the hydrocarbons, particularly the dissolving of the stopcock grease and the thermopile wax window. This dissolving eventually led to leaks in the thermopile housing which terminated the investigation. The maximum gas pressure attainable at room temperature is its vapor pressure of about $9.0 \mathrm{~cm}$. Actually, $3.8 \mathrm{~cm}$ of pressure was used with a radiation path length in the $\mathrm{CCl}_{4}$ of 460 centimeters, yielding the band shown in Fig. 3.

The fine structure apparent here was actually very real and is probably attributed to isotope effect. $\mathrm{Wu}$ and Sutherland ${ }^{18}$ have discussed in detail the isotope effect in $\mathrm{CCl}_{4}$ and have given quantitative results for the isotopic line separations of the fundamental bands. This band at $315 \mathrm{~cm}^{-1}$ is the low frequency triply degenerate fundamental vibration of symmetry type $F_{2}$, carbon tetrachloride belonging to the tetrahedral symmetry group. The abundance ratio of the isotopes of $\mathrm{CCl}_{4}$ is

$$
\begin{aligned}
\mathrm{CCl}_{4}{ }^{35}: \mathrm{Cl}^{17} \mathrm{CCl}_{3}{ }^{35}: \mathrm{Cl}_{2}{ }^{37} \mathrm{CCl}_{2}{ }^{35}: \mathrm{Cl}^{15} \mathrm{CCl}_{3}{ }^{37}: \mathrm{CCl}_{4}{ }^{37} \\
=31.6: 42.2: 21.1: 4.7: 0.4 .
\end{aligned}
$$

Considering the first three isotopes to be the only ones intense enough to yield a noticeable contribution to the absorption spectrum, one obtains a sixline spectra. The quantitative agreement of $\mathrm{Wu}$ and Sutherland's calculations with the curve of Fig. 3 are incompatible. Further experimental investigation of this band should be undertaken. The "Michigan" instrument with the proper care is capable of resolving the "isotope" fine structure nicely.

The near infra-red high resolution studies were done on the prism-grating instrument originally described by Hardy. ${ }^{19} \mathrm{~A} \mathrm{KBr}$ fore prism and a grating with 2400 lines per inch was employed. The limit of resolution of the instrument was just less than the fine structure for the type $A$ bands of $n$-butane. Propane had been previously studied by $\mathrm{Wu}$ and Barker ${ }^{20}$ so that only the bands of $n$-butane

${ }^{18}$ C. K. Wu and G. B. B. M. Sutherland, J. Chem. Phys. 6, 114 (1938)

19 J. D. Hardy, Rev. Sci. Inst. 1, 429 (1930).

${ }_{20} \mathrm{~V}$. Wu and E. F. Barker, J. Chem. Phys. 9, 487 (1941).
TABLE II. Distribution of the skeletal vibrations among the symmetry representations.

\begin{tabular}{lcllll}
\hline $\begin{array}{c}\text { Molecule of } \\
\text { symmetry }\left(C_{2 h}\right)\end{array}$ & $\begin{array}{c}\text { Total number of } \\
\text { skeletal vibrations }\end{array}$ & $A_{0}$ & $A_{\mu}$ & $B_{\theta}$ & $B_{*}$ \\
\hline$n$-Butane (trans) & 6 & 3 & 1 & 0 & 2 \\
$n$-Hexane & 12 & 5 & 2 & 1 & 4 \\
$\begin{array}{l}\text { Molecule of sym- } \\
\text { metry }\left(\bar{C}_{2 v}\right)\end{array}$ & $\begin{array}{c}\text { Total number of skel- } \\
\text { etal vibrations }\end{array}$ & $A_{1}$ & $A_{2}$ & $B_{1}$ & $B_{2}$ \\
Propane & 3 & 2 & 0 & 0 & 1 \\
$n$-Butane (cis) & 6 & 3 & 1 & 0 & 2 \\
$n$-Pentane & 9 & 4 & 1 & 1 & 3 \\
$n$-Heptane & 15 & 6 & 2 & 2 & 5 \\
\hline
\end{tabular}

TABle II $a$.

\begin{tabular}{lccccc}
\hline \hline$C_{2 v}$ & $E$ & $C_{2}$ & $\sigma_{x}$ & $\sigma_{y}$ & Activity \\
\hline$A_{1}$ & +1 & +1 & +1 & +1 & $I R, R$ \\
$A_{2}$ & +1 & +1 & -1 & -1 & $R$ \\
$B_{1}$ & +1 & -1 & +1 & -1 & $I R, R$ \\
$B_{2}$ & +1 & -1 & -1 & +1 & $I R, R$ \\
\hline$C_{2 h}$ & $E$ & $C_{2}$ & $\sigma_{h}$ & $i$ & Activity \\
\hline$A_{g}$ & +1 & +1 & +1 & +1 & $R$ \\
$A_{u}$ & +1 & +1 & -1 & -1 & $I R$ \\
$B_{g}$ & +1 & -1 & -1 & +1 & $R$ \\
$B_{u}$ & +1 & -1 & +1 & -1 & $I R$ \\
\hline
\end{tabular}

and $n$-pentane were investigated here. The band contours for $n$-butane are shown in Figs. 4, 5, 6, and 7 . The fine structure revealed here was not sufficiently reliable to give any more than a confirmation of the moments of inertia as obtained from other information but did allow one to classify the band as to its symmetry type. The center of each of these bands for $n$-butane occurred at $1342.9 \mathrm{~cm}^{-1}, 1295.6$ $\mathrm{cm}^{-1}, 1135.6 \mathrm{~cm}^{-1}, 956.5 \mathrm{~cm}^{-1}$, and $740.0 \mathrm{~cm}^{-1}$. The contours of these bands allow the assignment of the frequencies given in Table I. The representation $A_{u}$ is the usual type $C$ band, due to a change in electric moment perpendicular to the plane of symmetry giving rise to bands with a $Q$ branch, although not necessarily very distinct. The representation $B_{u}$ is a mixture of type $A$ and type $B$ bands giving rise to a contour of a hybrid nature. Type $A$ would exhibit a sharp $Q$ branch and type $B$ no $Q$ branch at all, so that the combination may be almost anything. There is some doubt as to the proper interpretation

TABLE III. Significance of the force constants for the skeletal frequency calculations for the paraffin hydrocarbons.

\begin{tabular}{ll}
\hline \hline Parameter & \multicolumn{1}{c}{ Significance } \\
\hline$k_{33}$ & Force constant between two $\mathrm{CH}_{3}$ groups \\
$k_{32}$ & Force constant between $\mathrm{CH}_{3}$ and $\mathrm{CH}_{2}$ groups \\
$k_{22}$ & Force constant between two $\mathrm{CH}_{2}$ groups \\
$k \beta_{323}$ & $\begin{array}{l}\text { Force constant for the valence angle deformation } \\
\text { involving } \mathrm{CH}_{3}-\mathrm{CH}_{2}-\mathrm{CH}_{3}\end{array}$ \\
$k \beta_{322}$ & $\begin{array}{l}\text { Force constant for the valence angle deformation } \\
\text { involving } \mathrm{CH}_{3}-\mathrm{CH}_{2}-\mathrm{CH}_{2}\end{array}$ \\
$k \beta_{222}$ & $\begin{array}{l}\text { Force constant for the valence angle deformation } \\
\text { involving } \mathrm{CH}\end{array}$ \\
$\beta$ & Valence angle \\
\hline \hline
\end{tabular}


TABLE IV. Skeletal frequency assignments for the normal paraffin hydrocarbons.

\begin{tabular}{lcccc}
\hline \hline Molecule & $\begin{array}{c}\text { Experimental } \\
\text { frequency } \\
\text { in cm }\end{array}$ & & $\begin{array}{c}\text { Assign- } \\
\text { ment }\end{array}$ & References \\
\hline Ethane & 993 & & - & $(21)$ \\
& & & $B_{1}$ & $(11)$ and this work \\
Propane & 1053 & & $A_{1}$ & \\
& 870 & & $A_{1}$ & \\
& 370.6 & & & \\
$n$-Butane & 1056 & Raman & $A_{g}$ & $(12),(20)$ and this work \\
& 956.4 & $I R$ & $B_{u}$ & \\
& 833 & Raman & $A_{g}$ & \\
& 319 & Raman & $A_{g}$ & \\
& 215 & $I R$ & $B_{u}$ & \\
$n$-Pentane & 1072 & & $B_{1} \quad(12),(13)$ and this work \\
& 1025 & & $A_{1}$ & \\
& 914 & & $B_{1}$ & \\
& 861 & & $A_{1}$ & \\
& 337 & & $A_{1}$ & \\
& 279 & & $B_{1}$ & \\
& 149 & & $A_{1}$ & \\
& & & & \\
\hline
\end{tabular}

* The choice of these frequencies will be discussed in more detail below

to be given to the band in the region of $740.0 \mathrm{~cm}^{-1}$. It appears as if it may be of symmetry type $B_{u}$ being considered as without a $Q$ branch. On the other hand, it might be thought of as two bands each exhibiting a $Q$ branch, at $747.8 \mathrm{~cm}^{-1}$ and at 733.2 $\mathrm{cm}^{-1}$. This author had decided that if it were a single band at $740.0 \mathrm{~cm}^{-1}$ it should belong to the $\mathrm{CH}_{3}$ rocking frequency, but this assignment appears inconsistent with other data indicating this frequency to be greater than $900 \mathrm{~cm}^{-1.8,10}$

For $n$-pentane the bands with centers at 1167 $\mathrm{cm}^{-1}, 1141.4 \mathrm{~cm}^{-1}, 1072 \mathrm{~cm}^{-1}$, and $914 \mathrm{~cm}^{-1}$ were surveyed. None of the bands could be resolved and each appeared to lack a $Q$ branch consisting only of two absorption maxima separated by about $10 \mathrm{~cm}^{-1}$. Often when the infra-red spectrum is given for pentane, there will be listed pairs of lines separated by about $10 \mathrm{~cm}^{-1}$. Each of these pairs of lines should in most cases be considered as a single band.

\section{ANALYSIS}

Several articles have appeared recently on the vibrational frequency assignments for the paraffin hydrocarbons ${ }^{8-11}$ with an attempt to systematize the spectra of the larger members of the paraffin series. This author has confined his attention to the analysis of the planar skeletal modes of vibration, neglecting the hydrogen vibrations and the out-ofplane motions. The paraffin hydrocarbon molecules forming the series, ethane, propane, butane, pentane, hexane, etc., are considered to be zigzag chains of methylene groups with a methyl group on each end. Ethane is formed of two methyl groups only. The carbon-carbon distance is taken as $1.54 \mathrm{~A}$ from electron diffraction and the bond angle as $111^{\circ} 30^{\prime}$ $\pm 2^{\circ}$. The skeletal modes of vibration concern only the relative motions of the $\mathrm{CH}_{3}$ and $\mathrm{CH}_{2}$ groups.

The method of symmetry coordinates discussed by Herzberg ${ }^{1}$ was used for setting up the secular determinants. The potential function was approximated with a valence force potential, each of which will be written down in the following discussion. These molecules will be considered to belong to either symmetry type $C_{2 v}$ or $C_{2 h}$, except for ethane which may be either $D_{3 h}$ or $D_{3 d}$. Table II gives the number of skeletal vibrations belonging to each representation.

The representations given in Table II have the meanings given in Table II $a$ :

The procedure followed was to determine precisely the potential constants for the first molecule in the series, and then approximate the potential constants of the next larger molecule with these. This then gives an indication of where the skeletal frequencies will lie for the more complicated molecule. The most probable choice of frequencies was made from the experimental data and the parameters adjusted by a least squares method to obtain the best fit of the calculated frequencies with the experimental. This procedure was repeated for each molecule through $n$-pentane, the calculations becoming too cumbersome beyond that point. The valence angle, $\beta$, for the angle between a methyl and two methylene groups or between three methylene groups was considered an additional parameter which was adjusted by the least squares method for each molecule. No distinction in the angle with its position in the chain was considered. The angle was implicit in the potential functions as written below but appears explicitly after the transformation to symmetry coordinates is made.

Table III gives the meaning of the parameters chosen for the potential functions. The choice of experimental frequencies made for the determina-

TABLE V. Comparison of the calculated with the experimental frequencies for the skeletal vibrations of the paraffin hydrocarbons.

\begin{tabular}{|c|c|c|c|c|c|}
\hline Molecule & $\begin{array}{c}\text { Experi- } \\
\text { mental } \\
\text { frequency } \\
\text { in } \mathrm{cm}^{-1}\end{array}$ & $\begin{array}{c}\text { Calculated } \\
\text { frequency } \\
\text { in } \mathrm{cm}^{-1} \\
\text { with } \beta \text { a } \\
\text { parameter }\end{array}$ & $\begin{array}{c}\text { Percent } \\
\text { deviation }\end{array}$ & $\begin{array}{c}\text { Calculated } \\
\text { frequency } \\
\text { in } \mathrm{cm}^{-1} \\
\text { with } \\
\beta=111^{\circ} 30^{\prime}\end{array}$ & $\begin{array}{c}\text { Percent } \\
\text { deviation }\end{array}$ \\
\hline Ethane & 993 & 993 & 0 & & \\
\hline Propane & $\begin{array}{l}1053 \\
870 \\
370.6\end{array}$ & $\begin{array}{l}1053 \\
870 \\
370.6\end{array}$ & $\begin{array}{l}0 \\
0 \\
0\end{array}$ & $\begin{array}{r}1053 \\
860 \\
375\end{array}$ & $\begin{array}{c}0 \\
1.1 \% \\
1.3 \%\end{array}$ \\
\hline $\begin{array}{l}n \text {-Butane } \\
\text { (trans-form) } \\
C_{2 h}\end{array}$ & $\begin{array}{l}1056 \\
956.4 \\
833 \\
319 \\
215\end{array}$ & $\begin{array}{r}1092 \\
941.9 \\
820.4 \\
306.4 \\
221.5\end{array}$ & $\begin{array}{l}3.4 \% \\
1.5 \% \\
1.5 \% \\
3.9 \% \\
3.0 \%\end{array}$ & $\begin{array}{l}1045 \\
959.9 \\
846.7 \\
290 \\
231.8\end{array}$ & $\begin{array}{l}1.04 \% \\
0.36 \% \\
1.64 \% \\
9.10 \% \\
7.80 \%\end{array}$ \\
\hline$n$-Pentane & $\begin{array}{r}1072 \\
1025 \\
914 \\
861 \\
337 \\
279 \\
143\end{array}$ & $\begin{array}{r}1091 \\
1015.7 \\
883.6 \\
874.3 \\
334.3 \\
254.5 \\
143.2\end{array}$ & $\begin{array}{l}1.8 \% \\
0.9 \% \\
3.3 \% \\
1.5 \% \\
0.8 \% \\
8.8 \% \\
0\end{array}$ & & \\
\hline
\end{tabular}




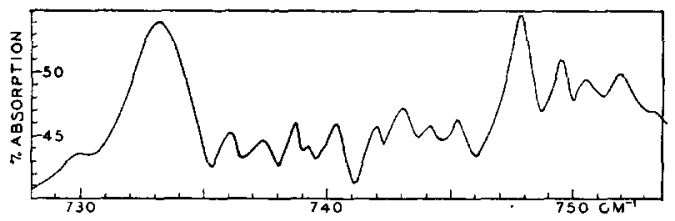

FIG. 4. $n$-Butane gas, $13.5-\mu$ band.

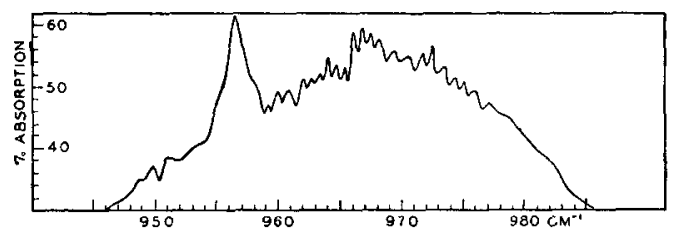

FIG. 5. $n$-Butane gas, $10.45-\mu$ band.

tion of the parameters in each potential function is given in Table IV.

Ethane.--This molecule has been rather completely discussed by Crawford, Avery, and Linnet ${ }^{21}$ and by Stitt. ${ }^{22}$ It has a single skeletal frequency at $993 \mathrm{~cm}^{-1}$ and gives the force constant $k_{33}$ to be $4.36 \times 10^{-5}$ dynes $/ \mathrm{cm}$.

Propane $\mathrm{C}_{3} \mathrm{H}_{8}$.-This molecule has been investigated under high resolution by $\mathrm{Wu}$ and Barker. ${ }^{20}$ They give for the fundamental frequencies 1053 $\mathrm{cm}^{-1}, 870 \mathrm{~cm}^{-1}$, and stated that they failed to find a band in the region of $370 \mathrm{~cm}^{-1}$. Kohlrausch and Köppl $^{12}$ reported a band at $373 \mathrm{~cm}^{-1}$ in the Raman spectrum. This investigation located a band in the infra-red for propane centered at $370.6 \mathrm{~cm}^{-1}$. Each of the following references included the analysis of propane in their study: $1,2,3,5,8,12,16,20,23$. The potential function chosen for this analysis is :

$$
2 V=2 k_{32}\left(\Delta r_{32}\right)^{2}+k_{\beta_{323}} l^{2}(\Delta \beta)^{2} .
$$

n-Butane $C_{4} H_{10}$. - There is possibility for this molecule that a mixture of four forms may exist : the trans- $\left(C_{2 h}\right)$ form, the cis- $\left(C_{2 v}\right)$ form, and two identical optical isomers of form $\left(C_{2}\right)$. Szasz, Sheppard, and Rank ${ }^{10}$ give evidence for the presence of the trans- $\left(C_{2 h}\right)$ form and the optical isomer of form $\left(C_{2}\right)$ in the liquid. For the infra-red spectrum of the gas it can be shown that all of the observed lines can be accounted for with the use of the $C_{2 h}$ model. The presence of another form in the gaseous state would give many more lines than have been observed. Information on $n$-butane has been given in each of these references: $1,2,3,5,8,10,12,16$, and 23 . The reason for the choice of frequencies used in the calculation was twofold. First, the force constants determined for propane were used for the butane calculation giving an indication of the position of the frequencies. Second, the division of the

${ }^{21}$ B. L. Crawford, W. H. Avery, and J. W. Linnett, J. Chem. Phys. 6, 682 (1938).

${ }_{22}$ F. Stitt, J. Chem. Phys. 7, 297 (1939). modes of vibration into two distinct representations restricted one to choose two frequencies from the infra-red data and three from the Raman for the molecular form $C_{2 h}$. The intensity of the lines aided further in the proper choice. The potential function for the $C_{2 h}$ and $C_{2 v}$ forms was taken as

$$
2 V=2 k_{32}\left(\Delta r_{32}\right)^{2}+k_{22}\left(\Delta r_{22}\right)^{2}+2 k_{\beta_{32} 2} l^{2}\left(\Delta \beta_{322}\right)^{2} .
$$

$n$-Pentane $C_{5} H_{12}$. - This molecule introduces the fourth and final new valence force constant necessary for the determination of the planar modes of vibration. Larger molecules in the series should involve the same type of four force constants, altered slightly to fit the particular molecule. The form of this molecule was chosen as $C_{2 v}$. References to previous data on $n$-pentane are: $1,3,8,9,12,16$, and 23. For $n$-pentane the choice of frequencies was considerably more difficult. Each normal mode is expected to be Raman active as well as infra-red active, and the comparison of each spectrum shows this correspondence. Since detailed measurements on the infra-red bands of $n$-pentane have not been made, one must rely upon the polarization measurements given by Fenske. ${ }^{23}$ The potential function used in this calculation was

$$
\begin{aligned}
2 V=2 k_{32}\left(\Delta r_{32}\right)^{2}+ & 2 k_{22}\left(\Delta r_{22}\right)^{2} \\
& +2 k_{322} l^{2}\left(\Delta \beta_{322}\right)^{2}+k_{\beta_{22} 2} l^{2}\left(\Delta \beta_{222}\right)^{2} .
\end{aligned}
$$

For propane, the calculated and experimental frequencies can be made to agree precisely if $\beta$ is used as the third parameter (see Table V). If one uses the angle $\beta=111^{\circ} 30^{\prime}$ given by electron diffraction, then the errors in the calculated frequencies are of the order of one percent. This is due to the simplicity of the potential function which must be considered only as an approximation. With the use of four adjustable parameters in the potential function of $n$-butane, the frequencies can be calculated

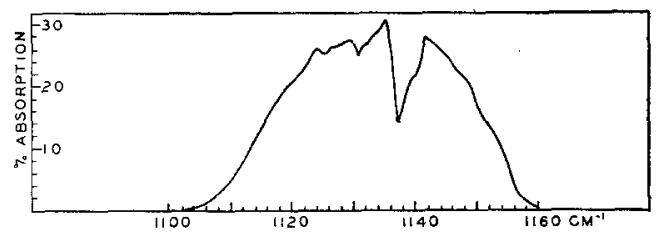

FIG. 6. $n$-Butane gas, $8.8-\mu$ band.

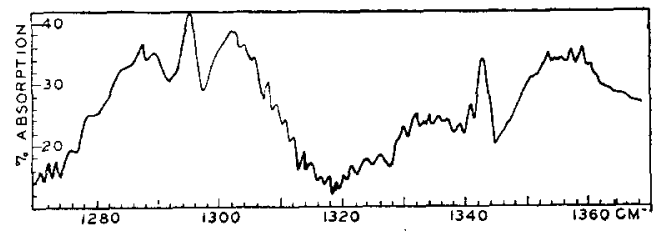

FIG. 7. $n$-Butane gas, 7.7- $\mu$ and 7.45- $\mu$ bands.

${ }^{23}$ M. R. Fenske, W. G. Braun, R. V. Wiegand, D. Quiggle, R. H. McCormick, and D. H. Rank, Anal. Chem. 19, 700 (1947). 
TABLE VI. Force constants for skeletal frequency calculations for the normal paraffin hydrocarbons.

\begin{tabular}{lccccc}
\hline \hline \multicolumn{1}{c}{ Molecule } & $k_{32} \times 10^{-5}$ & $k_{22} \times 10^{-5}$ & $k \beta_{822} \times 10^{-5} k_{\beta_{222}} \times 10^{-5}$ & $\beta$ \\
\hline $\begin{array}{l}\text { Ethane } k_{38}=4.36 \\
\text { Propane }\end{array}$ & 3.88 & & & & $180^{\circ}$ \\
$\begin{array}{l}n \text { - } \\
n \text {-Pentane }\end{array}$ & 3.80 & 3.525 & 0.333 & & $115^{\circ}$ \\
& 4.09 & 3.518 & 0.139 & 0.212 & $120^{\circ} 41^{\prime}$ \\
\hline
\end{tabular}

to better than four percent, which may be considered as satisfactory for a calculation involving the skeletal vibrations only. Using $\beta=111^{\circ} 30^{\prime}$ the errors become as large as 9 percent, because of an oversimplification of the potential function. The value of $\beta$ determined for each molecule has little physical significance, since it is actually only an adjustable parameter which corrects for the errors involved by using too simple a potential. The average valence angle probably increases slowly with increasing chain length, but not nearly as rapidly as these values of $\beta$ might seem to indicate. If one were to make the calculations using additional force constants or parameters of a different nature, then the errors could be taken up with them rather than with $\beta$. Furthermore, it must be continually kept in mind that the normal frequencies due to anharmonicities are, in general, not known to within percent deviations of the same order of magnitude as those associated with the calculated frequencies given here.

Table VI gives the values of the force constants and the angle $\beta$ adjusted by the least squares method. It would be thought that $k_{32}$ would approach a fixed value rather than increasing again in pentane. The other force constants change in the expected fashion. It is not possible to make a different choice of frequencies to bring this constant into line and, if the two frequencies $914 \mathrm{~cm}^{-1}$ and $861 \mathrm{~cm}^{-1}$ are interchanged with respect to their symmetry representations, the following force constants are obtained: $k_{32}=3.80 \times 10^{+5}$ dynes $/ \mathrm{cm}$, $k_{22}=3.57 \times 10^{5}, \quad k \beta_{322}=0.125 \times 10^{5}, \quad k_{\beta_{222}}=0.241$ $\times 10^{5}$, and $\beta=117^{\circ} 25^{\prime}$. The interchange of the frequencies $914 \mathrm{~cm}^{-1}$ and $861 \mathrm{~cm}^{-1}$ does not seem possible in view of the depolarization factors given by Fenske. ${ }^{23}$ It is felt that the skeletal normal frequencies for the larger paraffin hydrocarbons may be calculated by using the force constants determined here for $n$-pentane, with perhaps small changes applied to them. The infra-red and Raman spectrum of hexane should be extensively studied so that the symmetry classification of its frequencies may be made. This will enable one to continue this type of calculation to larger molecules with more assurance.

\section{ACKNOWLEDGMENTS}

I wish to express my sincere appreciation to Dr. David M. Dennison for suggesting this problem and to Dr. Ernest F. Barker for making available to me the equipment at the University of Michigan. I particularly wish to thank the National Institute of Health, Bethesda, Maryland, for the fellowship grant which enabled this research to be carried out. 